\title{
Climate Change and Justice between Nonoverlapping Generations
}

\begin{abstract}
It is becoming less and less controversial that we ought to aggressively combat climate change. One main reason for doing so is concern for future generations, as it is they who will be the most seriously affected by it. Surprisingly, none of the more prominent deontological theories of intergenerational justice can explain why it is wrong for the present generation to do very little to stop worsening the problem. This paper discusses three such theories, namely indirect reciprocity, common ownership of the earth and human rights. It shows that while indirect reciprocity and common ownership are both too undemanding, the human rights approach misunderstands the nature of our intergenerational relationships, thereby capturing either too much or too little about what is problematic about climate change. The paper finally proposes a way to think about intergenerational justice that avoids the pitfalls of the traditional theories and can explain what is wrong with perpetuating climate change.
\end{abstract}

Keywords: climate change, intergenerational justice, future generations, indirect reciprocity, common ownership, human rights

\section{Introduction}

When it comes to climate change, it is future generations who are likely to suffer most from both actions and omissions we, people living today, are responsible for. ${ }^{1}$ Unfortunately, and as dire as the situation threatens to be for them, we are not especially motivated to act on their behalf. There are a number of reasons why, in the case of future generations, we are particularly susceptible to what Stephen Gardiner has called moral corruption. ${ }^{2}$ Chiefly among them is that future generations are not around to challenge us. But another important

1 Let me say something about my use of 'generation.' There are a number of interesting ways this notion can be understood (for an exhaustive summary see Jörg Tremmel, Intergenerational Justice (London: Routledge, 2009), ch. 1; see also Stephen Gardiner, A Perfect Moral Storm. The Ethical Tragedy of Climate Change (New York: Oxford University Press, 2011), pp. 145-148), but the most common reading is probably that a generation maps on to reproductive cycles (between parents and children), usually separated by about 30 years. This would mean that an an given time up to four generations are alive and, when we are talking about intergenerational justice, we might be asking (a) what parents owe to their children, (b) what people owe to all those children, grandchildren, great grandchildren etc. of theirs who are alive during their lifetime, or-most generally-(c) what people of a specific age range owe to those who are significantly younger (or older) than they are but who happen to live at the same time. The latter is the sense of intergenerational justice we might deploy in the context of pension systems. By contrast, a concern with the long-term consequences of climate change requires us to employ another meaning of 'generation,' which renders all the aforementioned relationships intragenerational. What is at issue here is justice between nonoverlapping generations. This is because a response to climate change will often require consideration of generations far removed from each other in time. Although this is a somewhat artificial demarcation, unrealistically suggesting that the moment one generation dies, another one starts life on earth, it is here that most conceptual problems of intergenerational justice arise.

2 Gardiner (2011), pp. 301-338 


\section{CLIMATE CHANGE AND JUSTICE BETWEEN NONOVERLAPPING GENERATIONS}

reason, or so I claim, is that we lack a robust deontological theory of intergenerational justice. ${ }^{3}$

This is not because there are no such theories. It is rather because these theories, perhaps surprisingly, seem to have troubles showing what is wrong with climate change. And this, or so I contend, is a potentially serious problem, since climate change at least seems to be among the most pressing intergenerational issues to address. In this paper I show why existing theories of intergenerational justice cannot adequately identify developments such as climate change as wrongs and what a theory that can would have to look like.

My argument proceeds in three steps. In the first step I review three challenges involved in thinking about intergenerational justice, namely the 'no rights,' the 'nonidentity' and the 'epistemic' challenges. I argue that all of them are frequently (mis)taken as obstacles to whether there can be duties of justice to future persons in the first place, instead of being properly understood as simply three important ways in which our duties of justice to future generations are distinct from such duties to our contemporaries. In the second step I explore in more detail three of the most prominent deontological approaches to intergenerational justice, namely indirect reciprocity, common ownership of the earth and human rights, showing that none of them can properly identify climate change as violating our duties to future generations. In the third step I argue that we ought not conclude from this that there is nothing wrong with climate change on deontological grounds, but rather, that we need to think in new ways about what we owe to future generations. I spell out the chief intuition behind this claim and outline the lessons a compelling account of intergenerational justice should take away from the shortcomings of the existing approaches.

\section{Three 'Classic' Challenges to Formulating Theories of Intergenerational Justice}

There are three 'classic' challenges to identifying intergenerational duties that need to be addressed or at least kept in mind by anyone thinking about what we owe to future generations. These are the 'no rights,' the 'non-identity' and the 'epistemic' challenge, respectively.

Some have argued that because future persons do not currently exist, they can have no rights and thus no claims of justice against us. ${ }^{4}$ If this were true,

3 Consequentialist theories are often thought to imply that, since there will be so many more people (and other sentient beings) living in the future, the currently living could be asked to make great sacrifices to maximize or at least improve life for humans or even all sentient beings in a certain respect (wellbeing or happiness, for instance). Such theories want to bring about the best or, short of that, better consequences (with regard to whatever respect the particular consequentialist cares about) and are not primarily concerned with figuring out future generations' entitlements visà-vis ourselves. They thus require a separate discussion.

4 Wilfred Beckerman and Joanna Pasek, Justice, Posterity, and the Environment (Oxford: Oxford University Press, 2001), pp. 15-19. 
all one could try to show is that we owe those in the future, similar to Kant's imperfect duties, appropriate attitudes, but not specific actions or omissions. ${ }^{5}$

A popular example for illustrating the counter-intuitiveness of this claim is that of a bomb planted beneath a Kindergarten that will explode in six years. ${ }^{6}$ None of the five-year old children who will die in six years are currently alive. Someone claiming that nonexisting persons can have no rights would have to deny that these children's rights are being violated. They might have to say that not planting this bomb may be morally wrong quite generally or display an inappropriate attitude toward the future, but not something owed to the children as a matter of justice. They would have to treat the case of these fiveyear old children dying differently from the case of the 24-year old caretaker dying that day in the Kindergarten, who, unlike the children, was already alive (and clearly had rights) when the bomb was planted. Why this is implausible can be perhaps more clearly seen if we briefly reflect on which and whose rights are being violated and at what point in time. What right is the bomb-planter violating the moment she plants the bomb? Presumably not the right to life itself, for nobody dies that moment. But she is violating a right closely associated with the right to life, namely the right not to have another person avoidably act so as to create a severe risk to one's life. So even if, for some accidental reason, the bomb does not go off, the bomb-planter will arguably have done something seriously wrong. But who is the bomb-planter wronging at this point in time? By planting the bomb she is potentially subjecting many more people to the risk of dying six years later than will actually end up having their right to life violated. This means that she is wronging everyone who may end up being in that Kindergarten six years later. Included here are both existing persons as well as potential future persons, that is, everyone who will be a person at the time of the actual explosion and whose right to life will then be violated. This is because nobody is entitled to put another person's life at risk, regardless of the latter's ontological status any time prior to the risk materializing.

This is intended only to show that it is conceptually possible for currently nonexistent individuals to have rights and that, to the extent claims about justice involve claims about rights, that it is conceptually possible to speak of intergenerational justice as opposed to 'merely' about intergenerational beneficence or, more broadly and vaguely, intergenerational morality. What I have said thus far does not show, however, that all claim rights that contemporaries hold against each other can be easily transferred to intergenerational relationships. Quite to the contrary, it is one of the proposals in this paper that the different kinds of relationship

5 I am grateful to Laura Valentini for pressing me on this issue.

6 Joel Feinberg, Harm to Others (Oxford: Oxford University Press, 1987), p. 97. 


\section{CLIMATE CHANGE AND JUSTICE BETWEEN NONOVERLAPPING GENERATIONS}

lead to different kinds of duties. It turns out, for instance, that, when it comes to future persons, there will be many fewer duties of justice than we have toward our contemporaries and, as my discussion of the human rights approach will show, there may be reasons to be comparatively restrictive about what can count as a rights violation between nonoverlapping generations. This is connected to a further peculiarity of that relationship, to which I now turn.

Some might think that most of the more interesting questions raised in intergenerational relationships are not well captured by the case of the time-bomb. This is because in that case, the children's existence and identities are presumably independent of the act we are evaluating, namely that of planting a time-bomb. But many other cases are not like this, that is, many of the actions we perform today have profound effects on both the existence and identities of future persons. This raises the so-called non-identity problem ${ }^{7}$, which refers to the difficulty that it will frequently be impossible to show that we can harm future persons in the sense of making particular individuals worse off than they would have been had we acted otherwise. Even if we, for instance, chose catastrophic energy policies, those negatively affected could not really complain since any other energy policy would likely have led to a different set of future persons. Thus, nobody living today can intelligibly say that she would prefer to have been born into a world without climate change. While such an alternative world might be possible, it would almost certainly not contain her. If she were serious, therefore, she would be wishing for a world without herself in it.

In response, let me briefly return to the time-bomb example: Just assume that the particular children attending the Kindergarten on the day of the explosion would never have existed but for the planting of the bomb. Suppose, for instance, that the four children who died that day were quadruplets who would not have been conceived had the person who planted the bomb, who also happens to be the fertility doctor of the parents of these children, had been at the clinic that day instead of planting the bomb, since she-we know this for sure-would have used different embryos to implant (she had already set the embryos aside but had, nervous as she was about planting the bomb, neglected to tell her assistant, who promptly used the petri-dish with the non-selected embryos). Do we now think that there is nothing unjust about her planting the bomb given that those particular children who end up dying as a result would not have existed had she not planted that bomb? Surely not. The reason the answer must be negative is similar to the answer given above: the rights

7 Much of today's discussion of this problem goes back to Derek Parfit, Reasons and Persons (Oxford: Oxford University Press, 1984), p. 359. 
violated that day are not properly described as merely those of particular Anna's, Bertha's, Cecil's and Dorian's, who may indeed not be worse off than they would have been otherwise. The rights violated that day are those of the (abstract) persons these particular children are. Put differently, every person, independently of her particular identity and of whether she would have existed otherwise, has a right not to be killed by a deliberately planted bomb.

When it comes to the problem at hand, namely that of climate change and intergenerational justice, I am proposing that, pace what the rights and the nonidentity problems might suggest, it is not impossible for any particular future individual to plausibly say that it was unjust for a previous generation to avoidably produce circumstances in which she, as a person-whoever in particular she ends up being-is forced to live in a world marked by hardships that qualify as rights violations. The question then becomes a substantial one, namely what exactly an unacceptable hardship of this kind might consist of. Any account of intergenerational obligations therefore has to clearly spell out what circumstances (future) persons or generations have a right not to be subjected to by other (previously living) persons or generations.

We might say, for instance, as the accounts discussed below do, that it is unjust to leave future generations less than we inherited, that future generations are entitled to their fair shares of the earth or that future persons have (human) rights to life, health, and subsistence that we have to be careful not to undermine. These are all very different answers but each of them assumes that future persons can have rights that previous generations may violate and avoids having to show that a given future is comparatively worse than it could have been for anyone in particular.

The third challenge all accounts of what we owe to future generations need to contend with refers to there being serious epistemic limitations when it comes to determining the content of any obligation we might have to future generations. There are three aspects to this. First, we do not know how many future generations there will be. Second, it is unclear what anyone can know about future generations' values and preferences because there is no chance of directly exchanging our views with theirs. ${ }^{8}$ Third, it is difficult to tell what the precise consequences of our actions will be, especially when it comes to the further future.

That we do not know how many future generations there will be turns into a problem whenever we think that there is some finite good that everyone who ever lives has a claim to, since it is impossible to tell what each person's fair

8 On the political idea of addressing this problem by introducing representatives for future people see Anja Karnein, 'Representing Future Persons', in Axel Gosseries and Iñigo González (eds.), Institutions for Future Generations (Oxford: Oxford University Press, forthcoming). 


\section{CLIMATE CHANGE AND JUSTICE BETWEEN NONOVERLAPPING GENERATIONS}

share amounts to. Assuming that there will be an infinite number of future persons means that finite goods have to be infinitely divided, which amounts to something rather similar to not dividing them at all.

Moreover, it is very difficult to tell who in the future will want to have or need either certain shares of any particular resource or the enjoyment of specific landscapes or cultural artefacts. After all, 'wants are dependent on what is'9 and it is possible that "people in the future might learn to find satisfaction in totally artificial landscapes, walking on the astroturf amid the plastic trees while the electronic birds sing overhead'10.

By contrast, it is often considered fair to assume that we can know something about 'objective' or ahistoric interests future persons will predictably develop on account of certain anthropological features, such as the need for food, water, shelter and for being autonomous. ${ }^{11}$ But our inability to accurately predict the empirical consequences of our actions, especially when it comes to the further future, renders it difficult to know which policies may end up undermining these objective interests. Some might expect that before climate change has produced its greatest damage we will have found ways to either alleviate its effects or to successfully adapt to them. And, to the extent that history is a guide, this trust is not entirely unfounded. A number of unforeseeable innovations, such as the discovery of penicillin and advances in food production, for instance, brought about by industrialization, proved Thomas Malthus' initial predictions about the threat of overpopulation wrong. But this, of course, can go the other way as well: at the dawn of industrialization, for instance, nobody foresaw climate change as a consequence. $^{12}$

There is no perfect way to address the various aspects of the epistemic challenge, which sometimes may be taken to neutralize each other (not knowing how many future generations there will be may be counteracted by our not knowing what they may want or whether they will all want the same things anyway) or reinforce each other (only being able to say something about

9 Brian Barry, 'Sustainability and Intergenerational Justice', in Andrew Dobson (ed.), Fairness and Futurity, Essays on Environmental Sustainability and Social Justice (Oxford: Oxford University Press, 1999), 93-117.

10 Ibid.

11 Lukas Meyer and Dominic Roser, for instance, develop a sufficientarian account based on such objective interests. Lukas Meyer, and Dominic Roser, 'Enough for the Future', Critical Review of International Social and Political Philosophy 1 (2010), 219-248.

12 A common response to this problem is to advise acting on the precautionary principle. According to this principle, even if we are uncertain about particular future events and the long-term effects of our actions, we should try to prevent even a small chance of a major catastrophe occurring, especially if the costs of doing so are not excessive (Henry Shue, Climate Justice: Vulnerability and Protection (Oxford: Oxford University Press, 2014), pp. 308-309). This principle works well when we are thinking about risking irreversible catastrophe, which, as I claim in more detail below, is exactly the class of cases we should be most concerned about. 
minimal objective interests may be rendered entirely pointless if we cannot predict the consequences of our actions). If they are (individually or in any combination) given too much weight, there is virtually nothing anyone can say about our duties to future generations, even if someone were to remain convinced that we owe them something. If they are just ignored, then one is likely to propose duties that are easily refutable by anyone who can show how uncertain it is that the effects produced by compliance with these duties in the future will be the ones that were intended. Thus, and as will become apparent in what follows, most accounts of our intergenerational obligations run up against one or more aspects of this obstacle at some point or another.

All three challenges are quite real and the way they work is well appreciated. What is less well recognized is what they imply more generally. Usually, they are understood as obstacles to establishing duties of justice to future generations-as if there really was an alternative saying that our obligations to them, should there be any to begin with, amount to nothing more than matters of charity performed out of the goodness of our hearts. But that is not only intuitively implausible, it would also seem alien to well-established historical and cultural norms, for duties of justice to future generations have been recognized in most if not all cultures since at least biblical times (see, for instance, the reference to Leviticus below). Moreover, there is no good reason to feel any less obliged toward persons just because they are temporarily removed from us. All we need to know is that there will be persons. Thus, the mystery is not that we have duties of justice to future generations. Rather, what the rights-, nonidentity- and the epistemic challenges point to is that we have duties to persons with corresponding rights to whom we relate in a different (perhaps somewhat complicated) fashion - different, that is, from the way we relate to our contemporaries. What is at stake, therefore, is to show how the content of very familiar duties (and the corresponding rights) changes in the case of justice between nonoverlapping generations, not how these duties and rights vanish.

\section{Three Accounts of Intergenerational Justice}

My starting premise is that a compelling theory of intergenerational justice not only has to manoeuvre within the 'classical' constraints just mentioned, but also has to provide a plausible account of what is wrong with climate change. This is because our not combatting climate change is intuitively a - perhaps the paradigmatic case of intergenerational injustice. Similarly, if climate change is wrong on any account, future generations, who are likely to be the worst affected, seem to be the most obvious candidates. In the following I discuss three prominent theories of intergenerational justice, each of which, or so I claim, clearly fails to explain what is wrong with not combatting climate change. 


\section{CLIMATE CHANGE AND JUSTICE BETWEEN \\ NONOVERLAPPING GENERATIONS}

\section{Indirect Reciprocity}

That there is no opportunity for reciprocity or cooperation of any sort between nonoverlapping generations creates a problem for those who believe that moral norms derive from some form of agreement or contract about how the benefits and burdens of cooperation ought to be distributed. In response to this, a number of scholars have endorsed the concept of indirect reciprocity as a way to get around benefits (and damages) only flowing in one direction, namely forward in time. ${ }^{13}$

Indirect reciprocity, as a relational concept, reflects what one generation left or did for the next and asks the latter to reciprocate by doing (roughly) the same for the following generation. What one generation owes to the subsequent generation depends on the preceding generation in one of two possible ways. First, according to the literal or historical version, we owe to the following generation what we historically were left by the previous generation. Second, according to the hypothetical version, we owe to the following generation that which we would have wanted to have been left by the previous generation, ${ }^{14}$ or, perhaps more accurately, would have reasonably wanted to have been left. There are at least two problems with this account in its two versions, which I will label (a) the problem of indeterminacy and (b) the problem of scope.

(a) The problem of indeterminacy: In what follows I will show that due to the idea of indirect reciprocity being rather indeterminate, those versions that could account for what is wrong with climate change end up having to rely on an independent standard which renders the very idea of indirect reciprocity superfluous. Let me explain.

The literal reading implies that $\mathrm{B}$ should give to $\mathrm{C}$ what $\mathrm{B}$ received from $\mathrm{A} .{ }^{15}$ This sounds attractive, as nothing needs to be known to a generation besides what it inherited from the last and so the epistemic challenge is successfully circumvented-at least up to a point. There might still be questions about what may count as roughly equivalent between what people in the $18^{\text {th }}$ century left to those in the $19^{\text {th }}$ century and what this obliges those in the $19^{\text {th }}$ century to do for people living in the $20^{\text {th }}$. But what happens in the case of noncompliance? If generation A, for instance, destroys $20 \%$ of the world and thus leaves B with

13 John Rawls, Political Liberalism (New York: Columbia University Press, 1993); Barry (1999); John Rawls, Justice as Fairness: A Restatement (Cambridge, MA: Harvard University Press, 2001); Tremmel (2009); Matthias Fritsch, 'Asymmetrical Reciprocity and Intergenerational Justice', manuscript (2010), on file with author. Fritsch's arguments do not really apply to the case at hand (nonoverlapping generations) since he primarily considers how indirect reciprocity works between overlapping generations.

14 Rawls (1993), p. 274; Rawls (2001), p. 160.

15 I am leaving aside for the moment the question of what is meant by 'what we received,' that is, whether this refers to exactly what we received (same number of trees, birds, etc.), something that is of roughly the same value (fewer trees and birds, but more and better roads, for instance) or that we have to pass on a better world because we received an improved world ourselves (raising issues of commensurability between kinds of progress). 
an impoverished planet, it is rather unclear what B is obliged to do for C. Is $B$ permitted to do the same, namely to destroy another $20 \%$ of what would otherwise be left for the following generation $\mathrm{C}$ (and so on) or is B obliged to pass on the world as B inherited it (and thus behave better than generation A)?

If the former option is the correct implication of indirect reciprocity (permission to deplete), then the current generation would have a very good defence for not combatting climate change, at least as long as the destruction it thereby risked causing remained within its 'budget' of permissible destruction. If it was the latter (fully passing on whatever one inherited), the actual behaviour of the last (destructive) generation would not fully determine B's obligations. Rather, this version seems to be based on the independent idea that we have to preserve the world as we found it, as polluted or non-polluted it might have been at that moment. This would admittedly restrict our present-day emissions. However, the idea of preserving one's inheritance does not follow from the idea of indirect reciprocity, at least to the extent that 'reciprocity' reflects upon the behaviour of the past generation toward the present, which, in this case, would seem to include depletion.

The hypothetical version would also require the present generation not to further deplete the planet, regardless of what the previous generation did. It might even require the present generation to make up for some things the last generation depleted, although there may be a limit to this: If already the last generation received less than what they could have reasonably wanted, this would obviously impact what the current generation can reasonably expect from the previous generation - and should therefore pass on. This interpretation, too, would seem to place some constraints on the extent to which we can go on contributing to climate change.

Ultimately, however, this version also primarily relies on an independent standard, namely that of reasonableness and not so much on that of indirect reciprocity. That is, once we apply the standard of reasonableness the past generation should have adhered to (but did not follow) we can ask directly what it would be reasonable for future generations to expect from us (obviously given our specific situation which factually depends on how much we were left with by the past generation). As the content of what would have been reasonable to expect from the previous generation does not follow from its actual behaviour, the idea of reasonableness is freestanding in characterizing the adequate relationship between generations. ${ }^{16}$

16 We could note very abstractly that the reason we owe something to future generations at all is due to our having received something from previous generations. But even here it is not clear why the former should depend on the latter. 


\section{CLIMATE CHANGE AND JUSTICE BETWEEN NONOVERLAPPING GENERATIONS}

The same is true of Jörg Tremmel's interpretation, no part of which really follows from or depends upon indirect reciprocity. Tremmel claims that because our knowledge and experience accumulates with each generation and, for better or worse, there is no general tendency to unlearn things, there are autonomous factors of progress at work that each generation is obliged not to impede for the next (in response to the previous generation not having impeded it either). We might, for instance, think that bicycles are 'autonomously' transformed into automobiles in this way (and thus owed to the next generation), and, during the lifetime of one or several generations, these automobiles are 'autonomously' transformed into airplanes and so on. ${ }^{17}$ This would explain what is wrong with letting climate change occur: if, in general, each generation has to let 'autonomous' improvement occur, then climate change could be understood as a violation of this duty, at least to the extent that a destabilized climate may impede this improvement. However, because Tremmel would presumably hold that we should not impede this kind of progress even if past generations had done so, the idea of indirect reciprocity fails to do any kind of work. Rather, it is the idea of progress as placing demands on us (via reason) that would have to be fully spelled out.

(b) The problem of scope: To the extent that indirect reciprocity (on either version) can account for nonoverlapping generations at all, it can only do so for the relationships between adjacent generations, that is, between the current and the immediately following generation. However, as climate change shows, one generation can detrimentally impact the lives of many generations to come. And this need not occur in linear fashion, that is, the current generation might impact three generations from now to a much greater extent than the two immediately following generations-it may even be the case that not doing anything to combat climate change now may actually profit the immediately next generation. For a long time, that is, prior to the development of nuclear power and climate change, worrying only about adjacent generations may have been entirely sufficient, but it now no longer is. So even if indirect reciprocity was a historically viable option (which, for reasons stated above, is unlikely), it will not to be able to capture what is wrong with inaction in the face of the long-term effects of climate change.

Thus, there seems to be no reliable way for indirect reciprocity - alone, without the assistance of independent standards - to explain why contributing to climate change runs afoul of our intergenerational obligations.

17 Unfortunately, it is not clear that the transformations that regularly take place constitute an 'improvement.' To what extent, for instance, is the automobile really an improvement over the bicycle as a means of transportation? Industrialization is often taken as an 'improvement' of sorts and yet climate change is its flipside (to which cars contributes much more than bicycles), leaving many to wish they could turn back the wheels of time. And this is true of most innovations-it is debatable whether they are ultimately gifts or curses. 


\section{Common Ownership of the Earth}

Common ownership follows from the idea that all humans share the planet and that thus not one individual or one generation has any privileged access, certainly not just because they are born earlier. This seems to be a very promising proposal, at least at first glance. Unlike indirect reciprocity it provides us with guidelines as to what we need to bequeath to future generations, namely their fair shares, which do not depend on the actual behaviour of particular past generations. Furthermore, it does not limit the scope of our intergenerational obligations to the relationship between neighbouring generations.

That the earth was given to mankind in common is probably the oldest way of conceiving of intergenerational obligations. Passages in Leviticus, for instance, concerning the Jubilee ${ }^{18}$ can be read as a version of it (although here the distribuendum is only a particular part of the earth and was supposed to be divided only among a particular people). The suggestion is that each person who ever lives is entitled to her share of God's gift.

In Leviticus the continual preservation of the original state of the earth is presented in its most ideal, but therefore also most (empirically) implausible form. As Tremmel rightly points out, humans continually change and transform the earth, and, if there ever was a time when the aspiration was to merely preserve and maintain, this time has very long since passed. But quite apart from how realistic this original version may be, it already shows why common ownership may not be a particularly helpful framework for discussing the injustice involved in climate change. This is because to begin with, climate change is not likely to undermine a person's fair share of the planet; rather, it is likely to undermine the enjoyment of this share, about which common ownership seems, at least initially, to have little to say. ${ }^{19}$

This problem carries over to two more modern renditions of this idea. The first is from Thomas Paine (and, in his wake, several contemporary leftlibertarians, such as, most prominently perhaps, Hillel Steiner), the second is from Mathias Risse, who has recently tried to rehabilitate the idea of common ownership in his theory of global justice. These authors represent two diverging interpretations of the idea of common ownership. Paine embraces the traditional

18 'Consecrate the fiftieth year and proclaim liberty throughout the land to all its inhabitants. It shall be a jubilee for you; each of you is to return to your family property and to your own clan.' (Leviticus 25: 11). The 17th century Dutch biblical scholar Petrus Cunaeus (Peter van der Cun), interprets the Jubilee by noting that 'it is the task of the wise man (Moses) not only to set things in order for the present but to make decisions that will profit future generations' (Petrus Cunaeus, The Hebrew Republic (Jerusalem: Shalem Press, 2006), p. 15). We find a more recent expression of the idea that after a certain period things should be returned to their original state in Jefferson's thought that the earth belongs to the living (Thomas Jefferson, 'Letter to James Madison, September 6, 1789,' in Adrienne Koch (ed.), The Life and Selected Writings of Thomas Jefferson (New York: Random House, Modern Library Paperback Edition, 1998)).

19 There is at least one exception to this, which I will discuss below, namely the atmospheric capacity to absorb CO2. This is indeed a resource everyone is entitled to and which is threatened by climate change. 


\section{CLIMATE CHANGE AND JUSTICE BETWEEN NONOVERLAPPING GENERATIONS}

view that refers directly to the earth's resources. Risse has interpreted it to refer to original resources only to the extent they are needed to satisfy basic needs.

Paine argues that the first principle of civilization ought to be that 'the condition of every person born into the world, after a state of civilization commences, ought not to be worse than if he had been born before that period' ${ }^{20}$. He thinks that the earth in its natural, uncultivated, state belonged to the human race in common. ${ }^{21}$ Therefore, individuals in the civilized state can only ever have property in the value they add to the land, not the land itself. They thus owe a ground-rent for the land to the community as compensation for the loss sustained by some appropriating land and adding value to it by cultivating it. $^{22}$

A potential problem with this traditional interpretation of common ownership is that, as Paine himself notes, the value of human improvements is likely to by far exceed the value of the natural earth. ${ }^{23}$ This means that the ground-rent received by each person might be quite small in comparison to the accumulated wealth - and might continue to decline with an exponentially growing population. For scholars seeking to defend a global basic income, this may provide a promising starting point. But intergenerationally, this means that what is owed to future generations is likely to be minute compared to the holdings of the present generation. This is problematic because this implies that even significant kinds of destruction, caused, for instance, by climate change, may not count as jeopardizing this inheritance.

But even if this could be dealt with in some way, there is a more fundamental reason why this reading of common ownership will probably not generate a satisfactory account of what is wrong with climate change. Consider, for instance, the one resource that, in contrast to what I claimed earlier, would indeed appear to be threatened by climate change directly, namely the newly scarce atmospheric capacity to sequester $\mathrm{CO}_{2}$. As a common resource it ought to be fairly shared by all and Paine's scheme might initially meaningfully and possibly quite effectively be applied there. It would make emitting carbon more costly, as emitters would have to compensate the community for taking away some of what is commonly owned.

20 Thomas Paine, 'Agrarian Justice' in Philip S. Foner (ed.), The Complete Writings of Thomas Paine (New York: The Citadel Press, 1945), 609-623, p. 610

21 Ibid., p. 611

22 Because Paine thinks that it is not individual owners of landed property who are to blame but the system that erroneously allows them to have this property without leaving to others what is rightfully their share of the natural capital (and he wants to prevent violent uprising and confiscations of property), he suggests instituting a fund out of which each person on their twenty-first birthday should receive a one-time payment of fifteen pound sterling and every person reaching the age of fifty, ten pound sterling per annum. The fund should be financed by inheritance laws that take from the property bequeathed what is owed to the community (ibid., p. 613).

23 Ibid., p. 612 
Unfortunately, however, while this may make emitting more expensive, there seems to be no way to condemn the overconsumption and ultimately, depletion of this resource. ${ }^{24}$ What makes things worse is that not only can it not be replenished, it also, at least to date, has no substitute. This, however, implies that the compensatory scheme of the sort Paine has in mind will not reliably work in cases of finite resources, such as the atmospheric capacity to absorb $\mathrm{CO}_{2}$. It will thus not help save the planet from the most detrimental effects of climate change or explain what is wrong with not preventing them.

Perhaps we can stray a bit from Paine's understanding of common ownership of the earth as referring to the equal entitlement to (and compensation for the use of) original resources directly. Another way common ownership has been understood is by focusing on what a person's fair share of original resources allow her to do with them. Risse, for instance, argues that the earth belonging to mankind in common means that each person is entitled to those original resources and what he calls 'spaces' she needs to satisfy her basic needs. Common ownership thereby establishes a relationship between generations that leads to legitimate expectations on the side of future persons. In what Risse calls its abstract form, these expectations amount to the currently living being obliged not to take undue advantage of the asymmetry between generations. ${ }^{25}$ This abstract expectation leads to the more concrete obligation that, if possible, the current generation should leave to future generations original resources and spaces so that every person can satisfy her basic needs. ${ }^{26}$

This seems more promising than the traditional common ownership approach when it comes to explaining what is wrong with climate change. One might be able to say, for instance, that climate change risks undermining the ability of the present generation to insure that future generations are able to meet their basic needs. Moreover, this suggestion seems to provide a more flexible interpretation of common ownership than Paine has to offer and thus promises to avoid the problem of how to deal with only temporarily available (or, as in the case of land or oil, temporarily valuable) resources. This is because not all resources and spaces have to be divided among everyone for all time. Rather, persons are entitled only to those original resources they need to satisfy their

24 The carrying capacity of the atmosphere cannot be indefinitely replenished. The world as a whole arguably has a finite carbon budget of a trillion tons (that may not be exceeded for all time and all places). See <http://trillionthtonne. org/>.

25 Mathias Risse, On Global Justice (New Haven: Princeton University Press, 2012), p. 179.

26 Ibid., p.180. I am selecting those parts of Risse's argument that are important for my own. His overall claim is far more complicated. To the extent certain property regimes enable persons to fulfil their basic needs without access to original resources, for instance, these could be justified as well. He also proposes that one consequence of having a world divided into states (with the unequal distributions that follow from this division), is the obligation to make sure that human rights protecting institutions insure that each person's basic needs can be fulfilled and that such institutions are 'left' to future generations. 


\section{CLIMATE CHANGE AND JUSTICE BETWEEN NONOVERLAPPING GENERATIONS}

basic needs and not to any particular resource that may not be dividable across all time and all people. So we might be able to explain why, for instance, earlier generations, who had no use for the absorptive capacity of the atmosphere, were not entitled to it, whereas we, who do, are.

The chief problem is that Risse fails to explain why common ownership should amount to precisely this, that is, the requirement of meeting basic needs. What follows directly from a common ownership approach is this: every person who lives, has ever lived and will live on this planet is entitled to a fair share of original resources and spaces. What does not directly follow is this: every person is entitled to those original resources and spaces that are required to fulfil her basic needs. It is unclear where this last part comes from, that is, the part limiting a person's entitlement to those original resources and spaces required to fulfil her basic needs. If each person were entitled to her fair share of original resources then this could mean one of two things: with regard to replenishable resources this would imply that each person could take as much as she wanted - this would presumably exceed what a person needs to fulfil her basic needs. With regard to nonreplenishable items this would probably mean that each person was permitted to take only very tiny amounts, if any at all-this may mean that individuals were entitled to less than fulfilment of their basic needs would require.

This raises the question why Risse employs the idea of basic needs at all. I take it that the problems of coming up with convincing criteria of distributing the earth prompt Risse to embrace an entirely different framework, one that is just as essential to his thinking as common ownership is, namely that of human rights, which I discuss in the next section. So unfortunately, even if Risse's results are attractive and could explain what is wrong with climate change, they do not follow from common ownership. ${ }^{27}$

\section{Human Rights}

One increasingly fashionable way of addressing climate change is to argue for the protection of future generations' human rights, often taken to mean, more specifically, the right to satisfy basic needs. Simon Caney, for instance, claims that climate change threatens to undermine the human rights to life, health, subsistence and possibly the right to shelter of future persons. Take the

27 Although Risse spells out these fairly elaborate duties to future generations (with respect to basic needs, and, given the way the world is divided up into states, also with respect to certain institutional commitments that follow from this division but that I have not further elaborated on, see note 27) he realizes that the common ownership approach is rather limited in what it can do. He says, for instance, that 'the ownership approach does not generate strong duties to future generations' (Risse (2012), p. 168) Moreover, he also seems to rely heavily on the notion of 'reasonable conduct' as a further source of duties to future generations, which opens the door to many things out of reach for the common ownership account. 
human right to life. One way Caney maintains that it is clearly jeopardized by climate change' is that 'climate change will lead some to die because of an increase in the frequency and in the intensity of freak weather events. In particular hurricanes, storm surges and extreme precipitation will lead to direct loss of life.' ${ }^{28}$ Since the current generation is contributing to climate change, it is thereby responsible for human rights violations in the future. Caney's human rights approach thus focuses on those minimal objective interests that easily escape the epistemic challenge and convincingly argues that we have a duty not to undermine those interests if we can help it. There is little to disagree with here. Unlike indirect reciprocity and common ownership this approach clearly seems to capture an important aspect of what is wrong with climate change. Unfortunately, intergenerational interactions are not quite as straightforward and direct as Caney makes them out to be.

Consider Hurricane Katrina. Assume that it is true what some say, namely that it was caused by anthropogenic climate change. According to CNN, it (directly or indirectly) cost 1,833 lives. ${ }^{29}$ If Caney is right, here we have a clear case of human rights violations by previous generations who emitted $\mathrm{CO}_{2}$ and contributed to the events that triggered Katrina. 'Those who are alive at $t_{1}$ are under an obligation not to act in ways that will threaten the rights that persons at $t_{200}$ will hold. ${ }^{30}$ Although I generally agree that the currently living should not threaten the rights of future persons, I think that we may have to adjust our understanding of what constitutes such a threat when we are talking of causes and effects that may lie hundreds of years apart. In other words, it is not clear that Caney can really show that 'hurricanes, storm surges and extreme precipitation will lead to direct loss of life. ${ }^{31}$ That will certainly sometimes be the right description but only under certain circumstances, namely when, for instance, previous generations' contribution to climate change lead to events that inevitably - that is, without anyone being able to prevent this from happeningend up leading to the deaths of future persons. This does not appear to have been the case with Katrina. Or, if it was, then the bipartisan House Committee report 'A Failure of Initiative' is wrong when it fails to mention previous generations but instead solely blames the US government, saying that '[i]t remains difficult to understand how government could respond so ineffectively to a disaster that was anticipated for years, and for which specific dire warnings had been issued for days. This crisis was not only predictable, it was predicted.'32

28 Simon Caney, 'Human Rights, Responsibilities, and Climate Change', in Charles Beitz and Robert Goodin (eds.), Global Basic Rights (New York: Oxford University Press, 2009), 227-247, p. 230.

29 Available at <http://www.cnn.com/2013/08/23/us/hurricane-katrina-statistics-fast-facts/>.

30 Caney (2009), p. 235.

31 Caney (2009), p. 230, emphasis added.

32 Tom Davis, et al., A Failure of Initiative: The Final Report of the Select Bipartisan Committee to Investigate the Preparation for and Response to Hurricane Katrina, H. Rep. 109-396 (Washington: US Government Printing Office, 2006), p. xi. Available at <http://www.gpoacess.gov/congress/index.html>. 


\section{CLIMATE CHANGE AND JUSTICE BETWEEN NONOVERLAPPING GENERATIONS}

To the extent that Katrina was a result of anthropogenic climate change, it is probably accurate to say that previous generations contributed to it. But it would seem strange to make them responsible for the humanitarian disaster that followed or even to call their failure to prevent climate change the imposition of a threat to the rights of those affected. Arguably, it was not the extreme weather itself that wreaked havoc on the citizens. It was rather that the levees were not better protected and the response to the levees breaking too slow and too indecisive. In other words, in this intergenerational case, it is the intervening agency that carries a lot of the weight - more weight, that is, than it may carry in a purely intragenerational case.

Why might this be? One way to think about this difference is that in the relationship between nonoverlapping generations, unlike that between contemporaries, there comes a time when, within certain limits, the actions of those in the past become part of history, that is, quasi-external constraints the following generations will have to operate within and around. Then it may predominantly be a matter of intragenerational justice - justice between contemporaries - to make sure the world people live in, with all the baggage inherited from the past, is a safe and liveable one.

Suppose this is an adequate description, at least of how many people experience the actions of past generations and their own responsibility toward their contemporaries. Would they be right about this or should they be less willing to 'let bygones be bygones'? Speaking in purely pragmatic terms, it makes more sense, of course, to seek redress from people who are alive than from people who are dead. ${ }^{33}$ Moreover, if considered closely, it would presumably turn out that many things past generations did (or failed to do) could be viewed as violations of current or future persons' human rights. Building New York City, for instance, has had many effects on many generations. It is quite possible that more fatal events occurred than they would have if New York City had not been built. Still, few people would consider building New York City as an injustice toward those born later who died as a result. Apart from being pragmatic in the sense just mentioned, this can also be explained by pointing out that the sheer variety and frequency of ways in which previous generations could be blamed for what happens in the present (and in the future), would presumably render the exercise futile. ${ }^{34}$

33 At the same time, if we were more exacting with our dead, then we might also feel more of an obligation to the future. 34 Using New York City as an example was inspired by Dale Jamieson, who nicely describes the inevitable messiness of intergenerational relationships with reference to Manhattan, saying that 'because of the legacy bequeathed by past generations, people in Manhattan today can enjoy walking on the Highline, visiting the Metropolitan Museum of Art, and soaking up the ambience of Greenwich Village. However, the same generations that bequeathed this legacy destroyed the wild green paradise that had been bequeathed to them with its oysters the size of dinner plates, dense flocks of birds that darkened the sky, and rivers so thick with fish that they could be pulled out by hand' Dale Jamieson, Reason in A Dark Time. Why the Struggle Against Climate Change Failed And What It Means (Oxford: Oxford University Press, 2014), p. 159. 
The reader may think that one ought not be too lenient here; that, even if it were true that there is a general tendency to treat intergenerational cases of guilt-attribution differently from intragenerational cases, we should still be highly critical of this and not let past generations off the hook too easily. I am not, however, saying that there is no way for intergenerational human rights violations to occur or that actions that fall short of a human rights violation cannot be condemned as seriously morally wrong. All I am proposing is that there might be a significant and undesirable cost to not making human rights protection primarily a concern for intragenerational justice. The cost may be that, in a case like Katrina, for instance, the current government may not have to feel chiefly responsible for preventing events from unfolding that, it could claim, really was for past generations to avert. Thus, I am suggesting that we might do well to understand human rights violations - and rights violations more generally-in the intergenerational case more narrowly, that is, as requiring a rather direct cause and effect, where an action of the past would have to unavoidably and rather directly cause illness or death in the future. If we go this route, however, then very few intergenerational transactions will count as (human) rights violations.

Let me illustrate this with an example. Consider someone 100 years ago who publicly poisoned a well. Given that this was and continues to be public, a lot of things have to go wrong for a person today to drink of it: Perhaps it is not properly signposted, or perhaps there is nothing else left to drink. If it is not properly signposted, then the question is who is primarily to blame: the past public poisoner or those who failed to put up appropriate signs today? Perhaps we want to say that it is the primary responsibility of the past public poisoner if we think she did it just for the sake of hurting us or because she simply did not care. This might indeed be worse than if we knew that the past public poisoner had dedicated all her energies to developing a life-saving medicine and, without her knowing, one of the toxic by-products ended up seeping into the well. Then, as soon as she learnt about this she made it public in order for the world and all future generations to be warned. These varying narratives will make a difference to how we think of the poisoner. But given that everyone living today could be aware of the danger and that certain constraints are inevitably part of intergenerational interactions, ${ }^{35}$ it seems that it would make most sense to

35 Just think of industrialization and the amazing kinds of progress it has allowed us to make as well as how much damage it has caused. And these messy bundles are not merely modern phenomena. All the innovations brought about by the Romans, for instance, came with much destruction-by this I am referring not only to the wars, but also the tremendous ecological damage ancient Romans managed to inflict upon themselves and others. Take, for instance, Rome itself, which, due to deforestation, ended up being deadly in the summers, infested with Malaria-carrying mosquitos. See Robert Sallares, Malaria and Rome: A History of Malaria in Ancient Italy (Oxford, Oxford University Press, 2002) and Lara O’Sullivan, Andrew Jardin, Angus Cook and Philip Weinstein, 'Deforestation, Mosquitos, and Ancient Rome: Lessons for Today', BioScience 58/8 (2008), 757-760. 


\section{CLIMATE CHANGE AND JUSTICE BETWEEN NONOVERLAPPING GENERATIONS}

attribute primary responsibility to the person or agency currently responsible for erecting public warnings.

Note that I am not suggesting that there is no problem with people going around publicly poisoning wells - quite to the contrary, I believe that even where there is no duty of justice, people have strong moral obligations to avoid, whenever possible, the risk that their actions might, even via many detours, cause human suffering or even death now or in the future. I am only saying that transformations of the earth frequently lead to unknown and unforeseen side effects, which are inevitably part of the package we inherit. So just noting that some choices today are made harder, restricted or possibly more lethal due to what previous generations did, should not be enough to speak of a (human) rights violation.

Now suppose there is nothing else to drink and that this is the reason someone ends up drinking from the poisonous well. Then the question of who is to blame crucially depends on why there is nothing else for this person to drink, that is, whether (a) there is just no other water (either nobody has enough water or there is not enough healthy water for everyone) or (b) there is plenty of healthy water for everyone but it is badly distributed. If past generations had knowingly and avoidably made it the case that future persons had no choice but to die or drink poisoned water (and then die), they would clearly be responsible and guilty of a (human) rights violation, even on a narrow understanding on the term. Future persons arguably have a justified claim that previous generation do not knowingly and avoidably act so as to make it impossible-not merely somewhat more difficult ${ }^{36}$ - for future persons to meet their subsistence needs. But if this was a story about today, for instance, then the explanation would more likely be (b). It would then not be the past poisoner, as blameworthy as she might be, who is primarily responsible for the death of present pond-drinking people, but it is people living today who are distributing resources poorly so that some have no choice but to poison themselves.

Thus, while it would not be impossible for (narrowly understood) intergenerational rights violations to occur, there would have to be rather specific circumstances for this to happen. That is, the effects of previous generations' actions would have to be such that it would be impossible or at least extremely difficult for the potential victims themselves or their contemporaries to help avert the disaster. So even in the presence of climate

36 I say 'somewhat' because, as I will show in what follows, if, short of making it impossible, they made it very difficult it might indeed be a concern of justice. 
change, and as the example of Katrina illustrates, such cases would be rare. ${ }^{37}$

In sum, the human rights approach is perhaps the most promising of the approaches discussed so far - violating the human rights of future person would indeed constitute an injustice. But in the (wide) version currently proposed by Caney, it underestimates the inevitable messiness of intergenerational transactions and misconceives the directness of how nonoverlapping generations should relate to each other. It then captures too many kinds of intergenerational transactions. If understood narrowly, however, the way I am advocating, focusing on rights such as those Caney has in mind, namely those to life, health subsistence and shelter, captures too few cases and is thus unable to provide an account of what is wrong with cases of climate change that are not unavoidably catastrophic.

\section{What Do We Owe to Future Generations?}

My starting concern was that none of the existing accounts of intergenerational justice seems to be able to identify what is wrong with climate change. Indirect reciprocity requires independent standards, such as equality or reasonableness, to show what is wrong with climate change and has a scope that is too limited to capture the effects our behaviour has on future persons far removed from us. Common ownership, in turn, generates standards of intergenerational justice that are too undemanding to show that even some of the more detrimental effects of climate change are necessarily wrong. Concentrating on human rights violations, as least as understood by Caney, either stretches our notions of rights violations beyond what is desirable or identifies only very extreme cases in which climate change ends up unstoppably causing people to lose shelter, fall ill or die in the future.

There are two conclusions one could draw from these findings. First, one might question my starting premise, namely that not combatting climate change constitutes an intergenerational injustice. Perhaps the reasons we have for combatting it aggressively lie elsewhere. ${ }^{38}$ The alternative conclusion is that

37 Jamieson similarly suggests that direct interactions of the kind required for familiar kinds of wrongs, will be rare. He asks his readers to imagine a Doomsday device that will explode in 2100. Presumably, there is nothing the following generation could do to (a) stop it from exploding or (b) to protect people from it (by, for instance, either transporting it to the event horizon of a black hole or enabling humans to change galaxies). Jamieson claims that setting up this Doomsday device would mean that 'virtually all of life in the run-up to 2100 would be consumed by attempts to dismantle the device' (Jamieson (2014), p. 160). But he, rightly, I think, concludes by saying that the 'power that the present generation wields over posterity by changing climate, great as it is, is not sufficient' to produce this result (ibid.). This is because, unlike this Doomsday device, the world will vary according to the choices made by future generations.

38 Apart from intergenerational justice, there are a number of other important reasons why climate change may be unjust or ethically problematic. To the extent, for instance, that climate change has effects today it is aggravating the plight of the poor in the world and thus raises serious concerns of global justice (Henry Shue (2014) as well as Darrel Moellendorf, The Moral Challenge of Dangerous Climate Change (Cambridge: Cambridge University Press, 2014)). Moreover, as P.D. James and, more recently, Samuel Scheffler, have powerfully shown, it is our own values, which, inevitably involve caring about (a) there being a future and (b) this future being of a certain, familiar kind (P.D. James, The Children of Men (New York: Random House, 1992) and Samuel Scheffler, Death and the Afterlife (New York: Oxford University Press, 2013)). 


\section{CLIMATE CHANGE AND JUSTICE BETWEEN NONOVERLAPPING GENERATIONS}

we are still in need of an adequate theory of intergenerational justice, one that can plausibly capture what is wrong with not only inevitably catastrophic but also with less extreme climate change that is still within the power of future generations to mitigate and adapt to. This, I think, is the conclusion we ought to draw, since, as I briefly mentioned before, it would be ironic to think of climate change as wrong on many accounts but not on the one where it threatens to cause the most serious damage, namely future generations. Moreover, if a theory of intergenerational justice should rule out anything, it should presumably rule out the worst kind of impact current generations can have on the future.

If I am right about this, there are three lessons to learn from the failings of the theories of intergenerational justice I have discussed. After spelling these out I make my own attempt to explain what is wrong with climate change, keeping these lessons in mind.

An account that can capture what is specifically bad about an increasingly destabilized would, in response to the problems faced by the approaches discussed so far, have to proceed along the following three lines: it has to (1) focus on impact rather than on proximity, (2) embrace a threshold that is based on opportunities rather than on resources and (3) take into account the messyand indirectness of intergenerational relationships.

1. Impact- not Proximity-focused. Unlike indirect reciprocity, a plausible account has to provide a standard that treats the relationships between the current and any particular future generation as clearly separate from the relationship between the previous generation and the current. Once the relationships between different generations are disaggregated, it is possible to concentrate on individualized accounts of how different generations relate to each other. This is important because it is no longer the case that a generation is most likely - and should therefore avoid-to detrimentally impact the immediately following generation but not any generation beyond. Climate change, together with other far-reaching technologies such as nuclear power, has fundamentally altered this.

2. Opportunity (not Resource)-tied Threshold. Unlike common ownership, a plausible account has to take into consideration that there are few resources or other items that can be shared across all generations. And that relying only on those things that can, at least approximately, be shared over time will again lead to results that are not demanding enough to capture what is wrong with climate change. Moreover, when we worry about something like climate change this is not primarily because it signals an unfair division of the planet's resources. The unfair distribution, for instance, of the atmospheric capacity to 
absorb $\mathrm{CO}_{2}$, only seem to matter to the extent that we want or need to pollute the planet even more. So while it is very appealing to specify the content of intergenerational obligations by pointing to the planet and its resources, ultimately, what matters to our relationship to future generations is something different. It is, as both Caney and Risse point out, whether we did anything to undermine future generations' ability to lead a life of a certain quality. To the extent this quality requires the use of certain resources, we owe it to them (individually and collectively) not to avoidably deplete them. As already mentioned, this last point does not follow directly from the common ownership account. Rather, it is a mere reflection on what earlier generations owe to later generations on account of being able to impact them far beyond the inevitable and necessary.

3. Indirectness of Intergenerational Relationships. Unlike the rather minimal human rights approach Caney has to offer, a plausible account needs to distinguish between inevitable intergenerational transactions (including their messiness), on the one hand, and intergenerational transactions that go beyond this, on the other. If not, the theory risks either over-or underdetermining cases of intergenerational injustice, identifying most transactions as unjust or not being able to account for what is wrong with a phenomenon like climate change, at least as long as its effect are not unavoidably catastrophic. In order to successfully address this last point we also need to rethink the way we apply notions of responsibility in the intergenerational context. Although previous generations have always 'caused' future events, rendering themselves potentially vulnerable to being blamed (in cases in which these events turned out to have detrimental effects in the future), we have a tendency not to do so. And this, I have been arguing, probably for good reasons.

With these considerations in mind, I now provide a rather rough sketch of one possible way to think about what makes climate change, even short of having unstoppable consequences that are outright disastrous, into a case of intergenerational injustice.

Beyond causing a certain number of hardships and deaths in the future (which will always occur on account of choices made by previous generations), on the one hand, and large-scale destruction, on the other, climate change may lead to a situation in which later generations are no longer free to choose the course of their own individual and collective lives. They may, instead, be forced to dedicate their time and energy to addressing the various threats posed by an increasingly destabilized climate. Future persons may be born into a world in which, for instance, the only professions available are ones connected to trying to prevent the worst from happening or, if that is no longer possible, to find ways for humans to survive on an increasingly hostile planet. Unlike 


\section{CLIMATE CHANGE AND JUSTICE BETWEEN NONOVERLAPPING GENERATIONS}

other ways in which previous generations have always constrained the choices of those born later, future persons' lives may be no longer just be impacted, they may instead be to a large part determined by previous generations' failure to properly address intertemporally detrimental developments such as climate change.

So the problem does not just start when my continuing to emit unavoidably causes two deaths in the future (by, for instance, leading, via a chaotic chain of events, to lighting striking the tree they happen to be under). ${ }^{39}$ Rather, it already begins when my emissions contribute to a world in which future persons, due to very frequent extreme weather events, have to permanently worry about how to prevent lighting strikes or about where it is safe to be in order not to be struck by lightning.

This suggests that what we owe to future generations may be something very specific to intergenerational relationships, namely not to exert undue influence on them. It is the right not to have a previous generation determine and dictate the lives of future persons, that is, impact these lives beyond the inevitable ways they are always impacted. And, unfortunately, it seems that we - the current generation - may be well on our way to violating this right. ${ }^{40}$

To what extent does this right I am proposing take into consideration the lessons I delineated earlier? To begin with, this right to be free from undue influence would be of concern to current generations no matter which generations in the future are likely to be impacted and how far removed in time they may be. Its validity is, in principle at least, independent of whether any previous generations violated it or not. ${ }^{41}$ Moreover, demanding such a right would focus on what future generations are likely to be able to do, that is, what opportunities they have to lead self-directed and self-sufficient lives, rather than on which particular resources they may end up with. Finally, a right to be free from undue influence would be able to account for the messy- and indirectness of our intergenerational relationships by drawing attention to precisely the way climate change runs afoul of the conditions under which we ordinarily relate to future generations.

39 This is the case Caney would be concerned about if he adopted my narrow reading of intergenerational human rights violations.

40 Whether this is true or not obviously depends on certain empirical assumptions regarding what effects the climate change we are currently committed to producing will have on the future, that is, whether these effects will be such that future generations can simply deal with them in the course of leading their largely self-determined lived or ones that will require their full and undivided attention to mitigate or adapt to.

41 If we are forced to act in ways that lead to our dominating the future, it might turn out that we are already dominated by a previous generation. This would not excuse our behavior but it might bind our hand in ways that we cannot do much about. 
Much more would have to be said to defend this proposal properly. For instance, it would be important to discuss at greater length when 'impacting' the future-which I am claiming is inevitable - turns into 'determining' the future - which I am claiming violates future generations' rights. It would also be fair to question whether my proposed approach (or sketch of one) is not, while more inclusive than Caney's, nevertheless too narrow to be able to capture sufficient degrees of climate change as unjust. While I am claiming that, on my account, even non-catastrophic climate change, which future generations still stand a chance of mitigating and adapting to, can be deemed unjust, it is also true that, in order to lead to undue intergenerational influence, climate change cannot 'merely' have consequences in the future that may be difficult to deal with, but that remain quite manageable. To the extent, therefore, that my account appears too narrow, it, when fully spelt out, would have to be complemented by a theory of intergenerational morality, delineating appropriate attitudes toward the future. These would presumably ask previous generations to try to reduce their detrimental effects on the future, even if these effects fall short of anything that would constitute an injustice.

Thus, there is a lot of work remaining. All I wanted to do here is motivate the thought that a compelling account of intergenerational justice needs to be able to explain why climate change is different from other ways previous generations inevitably impact the lives of future generations and therefore qualifies as a case of intergenerational injustice, possibly the first genuine such case. ${ }^{42}$

\section{Anja Karnein \\ Department of Philosophy, \\ Binghamton University, SUNY \\ email:akarnein@binghamton.edu \\ the global justicenetuork}

42 For their helpful comments and criticisms I would like to thank the participants of Henry Richardson's and Terry Pinkard's seminar series 'Moral Innovation' at Georgetown University, the participants of Stephen Gardiner's workshop on Intergenerational Justice at the University of Washington, as well as the participants of Peter Singer's DeCamp Bioethics seminar and the members of the Climate Future Initiative at Princeton University. I am especially grateful to Mark Budolfson, Julian Culp, Augustin Fragnière, Nicholas Hall and Laura Valentini for their insightful comments on the written version of this paper and to Mattias Iser for his invaluable feedback throughout the writing process. 